\title{
openheart Systematic screening for cardiovascular risk at pharmacies
}

\author{
Miklos Rohla, ${ }^{1}$ Heinz Haberfeld, ${ }^{2}$ Helmut Sinzinger, ${ }^{3}$ Harald Kritz, ${ }^{4}$ \\ Maximilian Tscharre, ${ }^{1}$ Matthias K Freynhofer, ${ }^{1}$ Kurt Huber, ${ }^{1,5}$ Thomas W Weiss ${ }^{1,5}$
}

To cite: Rohla M, Haberfeld $\mathrm{H}$, Sinzinger $\mathrm{H}$, et al. Systematic screening for cardiovascular risk at pharmacies. Open Heart 2016:3:e000497.

doi:10.1136/openhrt-2016000497

Received 10 July 2016 Revised 28 July 2016 Accepted 8 August 2016

\section{CrossMark}

\section{${ }^{1} 3$ rd Medical Department, Cardiology and Intensive Care Medicine, Wilhelminen Hospital, Vienna, Austria ${ }^{2}$ Pharmacists College of Lower Austria, Vienna, Austria \\ ${ }^{3}$ Institute for Diagnosis and Treatment of Lipid Disorders and Atherosclerosis (ATHOS), Vienna, Austria \\ ${ }^{4}$ Wilhelm-Auerswald Atherosclerosis Research Group, Vienna, Austria ${ }^{5}$ Medical Faculty, Sigmund Freud University, Vienna, Austria}

Correspondence to Dr Miklos Rohla; miklos. rohla@meduniwien.ac.at

\section{ABSTRACT \\ Background: Early identification and treatment of cardiovascular risk factors (CVRFs) is essential to prevent excess morbidity, mortality and healthcare- related costs. We sought to investigate whether an active screening programme at pharmacies could identify a significant proportion of patients with previously undetected CVRFs.}

Methods and results: Between April and July 2013, 184 pharmacies in Lower Austria enrolled a total of 6800 participants, in whom body mass index (BMI), blood pressure (BP), total cholesterol and blood glucose were measured. Mean age was $58 \pm 17$ years and $67.8 \%$ were women. $21 \%$ of men and $16 \%$ of women had a BMI $\geq 30 \mathrm{~kg} / \mathrm{m}^{2}$. The crude prevalence of diabetes mellitus (DM) was $7 \%$, hypercholesterolaemia was identified in $57 \%$, and $44 \%$ had elevated BP. Among fasting individuals ( $n=1814)$, DM was found in $18 \%$. In total, $30 \%$ were confronted with a CVRF they were previously unaware of, and pharmacists recommended $45 \%$ of all participants to actively consult a physician. A first-time diagnosis of a CVRF was most frequent in the age groups between 25 and 64 (32\% of participants).

Conclusions: This pharmacy-based approach for cardiovascular risk screening found similar overall prevalences of CVRFs as reported by national surveys, but revealed underdiagnoses, particularly in lower age groups. A previously unknown CVRF was identified in every third individual, frequently prompting the pharmacists to recommend the consultation of a physician. An active screening approach at pharmacies might therefore serve as an effective alternative to the public preventive medical examination, particularly in younger age groups.

\section{INTRODUCTION}

The well established and potentially modifiable risk factors for cardiovascular (CV) morbidity hypertension (HTN), dyslipidaemia, diabetes mellitus (DM), obesity, improper diet and lack of regular physical activity account for $90 \%$ of population-attributable risk for both, stroke ${ }^{1}$ and myocardial infarction. $^{2}$ In other words, a dramatic $90 \%$ reduction of these events would be observed if the population were entirely unexposed to the mentioned risk factors.

\section{KEY QUESTIONS}

What is already known about this subject?

- Screening programmes for cardiovascular risk factors are poorly implemented into primary care, subsequently leading to a preventable excess in morbidity and mortality. Previous small studies not covering all major risk factors could show that pharmacies are feasible sites for screening.

What does this study add?

- The present study is one of the largest covering all major cardiovascular risk factors by instrument-based tests. One of the three participants was confronted with a major cardiovascular risk factor they were previously unaware of. The feasibility of this pharmacy-based approach is also underlined by a large sample that could be included in a short period of time.

How might this impact on clinical practice?

- A pharmacy-based screening approach might serve as an effective alternative to a public preventive medical examination in primary care, especially in younger age groups. Implementation into a national disease management programme would be required to achieve a population-based impact.

At present, these risk factors remain frequently unrecognised for years since screening programmes are poorly implemented into primary care, while screening for malignancies such as breast cancer, colorectal cancer or prostate cancer are widely accepted, actively offered and routinely performed in Western countries. $^{2-4}$ In Austria, $~ 13 \%$ of adults attend the annual, public and cost-free preventive medical examination. ${ }^{5}$ The transition from elevated $\mathrm{CV}$ risk to a manifest disease can be massively influenced by early identification and tight control of risk factors, which further underlines the relevance of active screening. ${ }^{6}$

Accordingly, we sought to investigate whether a standardised, active screening programme for CV risk factors (CVRFs) at pharmacies could identify a significant amount of previously unknown CVRFs. 


\section{METHODS}

\section{Study design and participants}

This cross-sectional study enrolled individuals who visited a participating pharmacy in Lower Austria between April and July 2013.

The Pharmacists College of Lower Austria, a province with a population of 1.6 million, invited all members (239 pharmacies) to participate.

There were no age-related or other inclusion/exclusion criteria prespecified. All participants provided informed consent, and only anonymised data were collected. In individuals below the age of 18, parental or guardian permission was obtained additionally.

All participating centres underwent investigator training where the study protocol, data collection as well as proper blood pressure (BP), glucose and cholesterol measurement were reviewed.

Using a standardised questionnaire, the following variables were assessed: age, gender, height, weight, waist circumference, fasting at the time of survey ( 8 hours without intake of food or liquids, except for water), tobacco use, seated BP, total cholesterol and capillary blood glucose. Individuals were surveyed whether a new CVRF was identified previously unknown to the participant (including conditions requiring an instrument-based test, thus, impaired fasting glucose (IFG), diabetes, elevated BP or hypercholesterolaemia; not including smoking and obesity). It was at the discretion of pharmacists to recommend the respective participant to actively consult a physician based on the detected CVRFs, and this decision was recorded in the survey.

\section{Diagnostic evaluations}

In accordance with the 2003 European Society of Hypertension (ESH)/European Society of Cardiology (ESC) Guidelines for the management of arterial HTN pharmacists were instructed to allow participants to sit for 3-5 min before beginning BP measurements and to take repeated measurements in case of inconsistent values. ${ }^{7}$ All pharmacists were experienced in the measurement of BP. An oscillometric semiautomatic sphygmomanometer was used at all sites (Boso Medicus, Jungingen, Germany or Hartmann Tensoval, Wiener Neudorf, Austria).

Total cholesterol and capillary blood glucose were measured locally using point of care devices (Accuntrend plus and Accu Chek Performa, Roche Diagnostics, Austria).

Waist circumference was measured midway between the uppermost border of the iliac crest and the lower border of the costal margin, obtaining the greatest possible circumference in expiration.

\section{Statistical analysis}

Discrete characteristics are expressed as frequency counts and percentages, and differences between groups were determined by the $\chi^{2}$ test. Continuous, normally distributed variables were expressed as means with SDs, unless otherwise specified. Differences were examined using the Student's t-test or the Mann-Whitney test, where appropriate. Correlations were reported as Spearman's coefficient. The level of significance used for all tests was a two-sided $p$ value of 0.05 .

The Software Package for Social Sciences V.22 (SPSS, Chicago, Illinois) was used for all statistical calculations.

\section{Outcome measures}

Obtained outcomes are reported for the whole cohort as well as according to gender and the prespecified age groups $<45,45-64$ and $>64$ years. ${ }^{8}$

In accordance with the $2013 \mathrm{ESH} / \mathrm{ESC}$ Guidelines for the management of arterial HTN, elevated office BP was reported at a threshold of $\geq 140 \mathrm{~mm} \mathrm{Hg}$ systolic (SBP) and $\geq 90 \mathrm{~mm} \mathrm{Hg}$ diastolic (DBP). ${ }^{9}$

On the basis of the $2011 \mathrm{ESC} /$ European Atherosclerosis Society (EAS) guidelines, hypercholesterolaemia was reported at a threshold of $\geq 200 \mathrm{mg} / \mathrm{dL}(5.2 \mathrm{mmol} / \mathrm{L}){ }^{10}$

According to the 2013 ESC Guidelines on diabetes, prediabetes and CV diseases (CVD), fasting capillary glucose values $\geq 101 \mathrm{mg} / \mathrm{dL} \quad(5.6 \mathrm{mmol} / \mathrm{L})$ and $\geq 117 \mathrm{mg} / \mathrm{dL}$ $(6.5 \mathrm{mmol} / \mathrm{L})$ were indicative of IFG and manifest DM, respectively. In non-fasting patients, glucose levels $\geq 200 \mathrm{mg} / \mathrm{dL}(11.1 \mathrm{mmol} / \mathrm{L})$ were regarded for the diagnosis of DM. ${ }^{11}$

Abdominal obesity was reported in the presence of a waist circumference $\geq 100 \mathrm{~cm}$ for men and $\geq 90 \mathrm{~cm}$ for women.

The study protocol conformed to the ethical guidelines of the 1975 Declaration of Helsinki as reflected in an approval by the Institution's Human Research Committee. $^{12}$

\section{RESULTS}

From 239 pharmacies in Lower Austria, 184 (77\%) participated in the recruitment of patients. In total, 6800 patients were included between April and July 2013, reflecting a recruitment of $36.9 \pm 43.5$ patients per site. The mean age was $58 \pm 17$ years, $67.8 \%$ were women. Twenty-two per cent of participants were below 45 years of age.

The mean BP was $134 \pm 21 / 81 \pm 12 \mathrm{~mm} \mathrm{Hg}$, mean capillary glucose $112 \pm 29 \mathrm{mg} / \mathrm{dL}$ (not account for fasting status), and mean total cholesterol was $210 \pm 43$, respectively (table 1).

\section{Obesity}

As presented in table 2, $48 \%$ of women and $66 \%$ of men were overweight (body mass index $(\mathrm{BMI}) \geq 25 \mathrm{~kg} / \mathrm{m}^{2}$ ) or obese $\left(B M I \geq 30 \mathrm{~kg} / \mathrm{m}^{2}\right)$. For both genders, the correlation between BMI and waist circumference was significant $\left(r_{s}=0.79, p<0.01\right.$ for women, $r_{s}=0.76, p<0.01$ for men). By use of the aforementioned cut-off values, the prevalence of abdominal obesity was similar between the genders $(49.3 \%$ vs $49.5 \%, \mathrm{p}=0.89$, waist circumference women $89.9 \pm 13.8$, men $99.4 \pm 12.7$ ). 
Table 1 Clinical characteristics of the cohort, stratified by gender

\begin{tabular}{lllll}
\hline & $\begin{array}{l}\text { All } \\
\mathbf{n = 6 8 0 0}\end{array}$ & $\begin{array}{l}\text { Men } \\
\mathbf{n = 2 1 9 3}\end{array}$ & $\begin{array}{l}\text { Women } \\
\mathbf{n = 4 6 0 7}\end{array}$ & p Value \\
\hline Age & $58 \pm 17$ & $60 \pm 17$ & $57 \pm 18$ & $<0.01$ \\
Age group & & & $<0.01$ \\
$\quad<45$ & $22.0 \%$ & $19.7 \%$ & $23.1 \%$ & \\
$45-64$ & $37.0 \%$ & $35.8 \%$ & $37.6 \%$ & $<0.01$ \\
$>64$ & $40.9 \%$ & $44.5 \%$ & $39.3 \%$ & $<0.01$ \\
Height & $168 \pm 9$ & $175 \pm 9$ & $164 \pm 7$ & $<0.01$ \\
Weight & $73 \pm 16$ & $83 \pm 16$ & $69 \pm 13$ & $<0.01$ \\
BMI & $26.02 \pm 4.67$ & $27.09 \pm 4.57$ & $25.51 \pm 4.64$ & $<0.01$ \\
Waist circumference & $93 \pm 14$ & $99 \pm 13$ & $90 \pm 14$ & $<0.01$ \\
SBP & $134 \pm 21$ & $139 \pm 20$ & $132 \pm 21$ & $<0.01$ \\
DBP & $81 \pm 12$ & $83 \pm 12$ & $81 \pm 12$ & $110 \pm 26$ \\
Glucose (capillary) & $112 \pm 29$ & $116 \pm 33$ & $214 \pm 43$ & \\
Total cholesterol & $210 \pm 43$ & $201 \pm 40$ & & \\
\hline BMI, body mass index; DBP, diastolic blood pressure; SBP, systolic blood pressure. & & \\
\hline
\end{tabular}

Table 2 The prevalence of CVRFs, stratified by gender

\begin{tabular}{|c|c|c|c|c|}
\hline & All $(n=6800), \%$ & Male $(n=2193), \%$ & Female $(n=4607), \%$ & p Value \\
\hline \multicolumn{5}{|l|}{ Obesity, BMI (kg/m²) } \\
\hline$<25$ & 46.6 & 34.0 & 52.6 & \multirow[t]{3}{*}{$<0.01$} \\
\hline $25-29$ & 35.9 & 45.1 & 31.5 & \\
\hline$\geq 30$ & 17.5 & 21.0 & 15.8 & \\
\hline \multicolumn{5}{|l|}{ Waist circumference (cm) } \\
\hline Men $\geq 100$, women $\geq 90$ & 49.4 & 49.5 & 49.3 & 0.89 \\
\hline Smoking & 17.9 & 19.5 & 17.2 & 0.02 \\
\hline \multicolumn{5}{|l|}{ Elevated BP (mm Hg) } \\
\hline$\geq 140 / 90$ & 44.0 & 52.0 & 40.3 & $<0.01$ \\
\hline \multicolumn{5}{|c|}{ Diabetes_only fasting patients $(\mathrm{n}=1814,26.7 \%)(\mathrm{mg} / \mathrm{dL})$} \\
\hline Normal $(<101)$ & 53.9 & 46.4 & 57.6 & \multirow[t]{3}{*}{$<0.01$} \\
\hline IFG (101-116) & 28.2 & 31.3 & 26.6 & \\
\hline Diabetes $(\geq 117)$ & 18.0 & 22.2 & 15.9 & \\
\hline \multicolumn{5}{|l|}{ Diabetes_all patients (mg/dL) } \\
\hline Normal $(<101)$ & 86.0 & 82.5 & 87.7 & \multirow[t]{3}{*}{$<0.01$} \\
\hline IFG (101-116) & 7.5 & 8.6 & 7.0 & \\
\hline Diabetes $(\geq 117)$ & 6.5 & 8.9 & 5.3 & \\
\hline \multicolumn{5}{|l|}{ Hypercholesterolaemia (mg/dL) } \\
\hline $\mathrm{TC} \geq 200$ & 57.2 & 47.6 & 61.6 & $<0.01$ \\
\hline \multicolumn{5}{|l|}{ Number of CVRF present ${ }^{\star}$} \\
\hline Any & 74.7 & 74.6 & 74.8 & 0.54 \\
\hline 0 & 25.3 & 25.4 & 25.2 & \multirow[t]{4}{*}{$<0.01$} \\
\hline 1 & 42.6 & 41.3 & 43.2 & \\
\hline 2 & 28.1 & 27.9 & 28.1 & \\
\hline 3 & 4.1 & 5.3 & 3.5 & \\
\hline Any new CVRF diagnosis* & 29.5 & 29.7 & 29.4 & 0.82 \\
\hline Recommendation to consult physician & 45.0 & 43.4 & 45.7 & 0.07 \\
\hline
\end{tabular}

*Including IFG, diabetes, BP, TC, but not smoking or obesity.

BMI, body mass index; BP, blood pressure; CVRF, cardiovascular risk factor; IFG, impaired fasting glucose; TC, total cholesterol.

\section{Diabetes mellitus}

Fasting and non-fasting participants were similar regarding age $(57.3 \pm 17.2$ vs $58.2 \pm 17.4, \quad \mathrm{p}=0.06)$, gender $(\mathrm{p}=0.29)$, BMI $(\mathrm{p}=0.49)$, waist circumference $(\mathrm{p}=0.17$ for men, $\mathrm{p}=0.59$ for women), total cholesterol $(\mathrm{p}=0.13)$, and DBP $(\mathrm{p}=0.41)$, but not SBP $(136.9 \pm 22.3$ vs 133.6 $\pm 20.4, \mathrm{p}<0.01)$. Mean capillary glucose was $114.4 \pm 30.1 \mathrm{vs}$ $103.7 \pm 22.1 \mathrm{mg} / \mathrm{dL}$ in non-fasting and fasting 
participants, respectively. Considering only fasting individuals $(n=1814)$, IFG and manifest DM were found in $28 \%$ and $18 \%$ of participants, respectively.

As indicated in figure 1 , there was a stepwise increase in the prevalence of DM with each age group, reaching

Prevalence of diabetes (only fasting patients, $n=1814,26.7 \%$ )

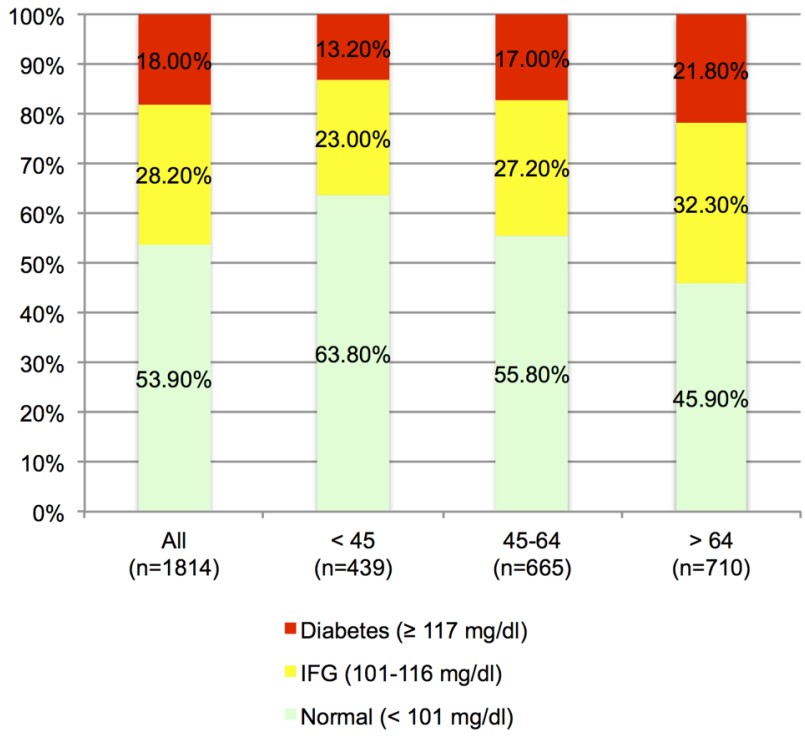

Figure 1 The prevalence of impaired fasting glucose (IFG) and diabetes mellitus in fasting participants (capillary glucose values).
$22 \%$ for fasting participants aged 65 and above ( $p$ for trend $<0.01)$.

When taking the full cohort in to account, manifest $\mathrm{DM}$ (capillary glucose $\geq 200 \mathrm{mg} / \mathrm{dL}(11.1 \mathrm{mmol} / \mathrm{L})$ in non-fasting participants) was observed in $6-8 \%$ of individuals (table 3).

\section{Elevated BP}

Elevated BP was infrequent below the age of 25, and absolute BP values were only modestly increased in individuals exceeding the $\mathrm{BP}$ threshold in this age group (144 $\pm 19 / 87 \pm 12 \mathrm{~mm} \mathrm{Hg}$, figure 2). Thereafter we observed a steep increase in the prevalence of uncontrolled HTN, affecting every second patient $\geq 45$ years of age. In these uncontrolled patients, mean BP values were $153 \pm 16 / 89 \pm 12$. Two-thirds remained in HTN grade 1 , that is, below $160 / 100 \mathrm{~mm} \mathrm{Hg}$. The increase in pulse pressure, that is, decline of DBP was observed starting at an age of 63 ( $\mathrm{p}$ for trend $<0.01$ ).

\section{Hypercholesterolaemia}

The crude prevalence of hypercholesterolaemia was $57 \%$.

Seventeen per cent of predominantly non-obese participants below the age of 25 had total cholesterol levels above $200 \mathrm{mg} / \mathrm{dL}(5.2 \mathrm{mmol} / \mathrm{L})$.

The peak prevalence of $65 \%$ was seen in the age group between 45 and 64 years (mean total cholesterol $217 \pm 42 \mathrm{mg} / \mathrm{dL}$ ), declining thereafter (figure 3). Data on cholesterol-lowering treatment in the respective subgroups were not available.

Table 3 The prevalence of CVRFs according to prespecified age groups

\begin{tabular}{|c|c|c|c|c|c|}
\hline & $\begin{array}{l}\text { All }(n=6800) \text {, } \\
\%\end{array}$ & $\begin{array}{l}<45(n=1499), \\
\%\end{array}$ & $\begin{array}{l}\text { 45-64 }(n=2517), \\
\%\end{array}$ & $\begin{array}{l}>64 \quad(n=2784), \\
\%\end{array}$ & $\begin{array}{l}\mathrm{p} \\
\text { Value }\end{array}$ \\
\hline \multicolumn{6}{|l|}{ Obesity, BMI (kg/m²) } \\
\hline$<25$ & 46.6 & 64.5 & 44.9 & 38.6 & \multirow[t]{3}{*}{$<0.01$} \\
\hline $25-29$ & 35.9 & 24.9 & 35.5 & 42.2 & \\
\hline$\geq 30$ & 17.5 & 10.6 & 19.7 & 19.2 & \\
\hline \multicolumn{6}{|l|}{ Waist circumference (cm) } \\
\hline Men $\geq 100$, women $\geq 90$ & 49.4 & 24.9 & 49.0 & 62.4 & $<0.01$ \\
\hline Smoking & 17.9 & 33.4 & 22.2 & 5.7 & $<0.01$ \\
\hline \multicolumn{6}{|l|}{ Elevated BP $(\mathrm{mm} \mathrm{Hg})$} \\
\hline$\geq 140 / 90$ & 44.0 & 23.8 & 43.3 & 55.6 & $<0.01$ \\
\hline \multicolumn{6}{|c|}{ Diabetes_only fasting patients $(\mathrm{n}=1814,26.7 \%)(\mathrm{mg} / \mathrm{dL})$} \\
\hline Normal $(<101)$ & 53.9 & 63.8 & 55.8 & 45.9 & \multirow[t]{3}{*}{$<0.01$} \\
\hline IFG (101-116) & 28.2 & 23.0 & 27.2 & 32.3 & \\
\hline Diabetes $(\geq 117)$ & 18.0 & 13.2 & 17.0 & 21.8 & \\
\hline \multicolumn{6}{|l|}{ Diabetes—all patients (mg/dL) } \\
\hline Normal $(<101)$ & 86.0 & 88.3 & 86.7 & 84.1 & \multirow[t]{3}{*}{$<0.01$} \\
\hline IFG (101-116) & 7.5 & 6.7 & 7.2 & 8.2 & \\
\hline Diabetes $(\geq 117)$ & 6.5 & 5.0 & 6.1 & 7.7 & \\
\hline \multicolumn{6}{|l|}{ Hypercholesterolaemia (mg/dL) } \\
\hline $\mathrm{TC} \geq 200$ & 57.2 & 33.8 & 65.3 & 61.5 & $<0.01$ \\
\hline Any new CVRF diagnosis* & 29.5 & 28.6 & 32.4 & 27.4 & $<0.01$ \\
\hline $\begin{array}{l}\text { Recommendation to consult } \\
\text { physician }\end{array}$ & 45.0 & 23.7 & 49.4 & 52.4 & $<0.01$ \\
\hline
\end{tabular}




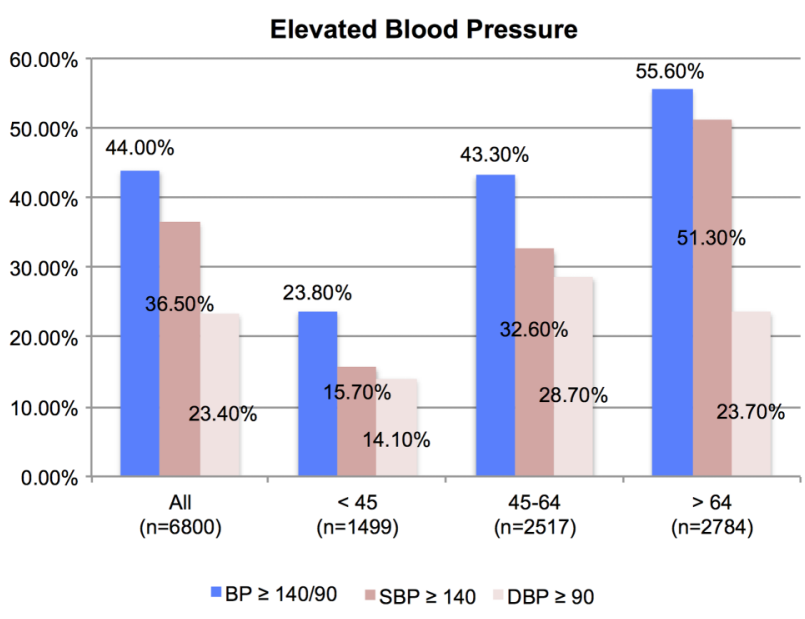

Figure 2 The proportion of participants with elevated BP values at a threshold of $\geq 140 / 90 \mathrm{~mm} \mathrm{Hg}$. BP, blood pressure; $\mathrm{DBP}$, diastolic blood pressure; SBP, systolic blood pressure.

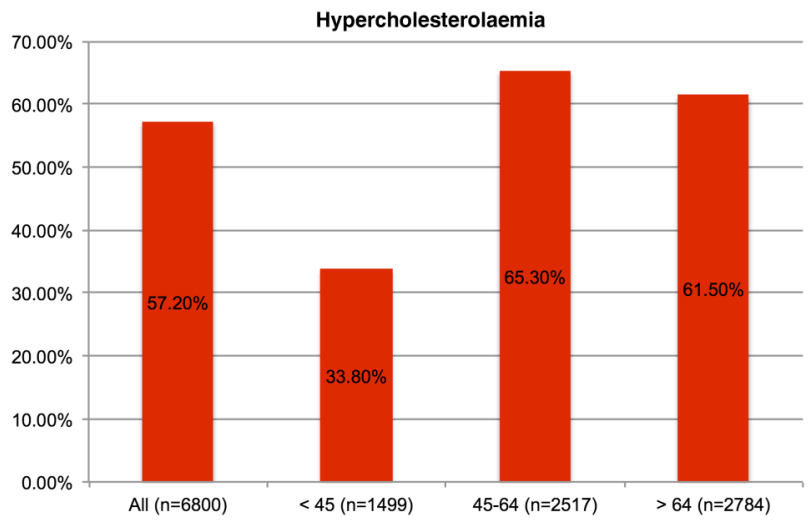

Figure 3 The prevalence of hypercholesterolaemia at a threshold of $200 \mathrm{mg} / \mathrm{dL}(5.2 \mathrm{mmol} / \mathrm{L})$.

\section{Smoking}

Ten per cent of minors reported to be active smokers; however, the sample size was non-representative $(n=70)$ in this age group. The prevalence of tobacco use was stable at a high level $(35 \%)$ in participants between 18 and 44 years of age, and men were somewhat more likely to report smoking compared with women (tables 2 and $3,39 \%$ vs $33 \%, \mathrm{p}=0.03)$. This trend continued in participants $\geq 45$ years at a lower overall prevalence $(15 \%$ vs $13 \%, \mathrm{p}=0.02)$.

\section{Total CV risk and identification of previously unknown risk factors}

The survey question regarding newly identified CVRFs related to the instrument-based parameters BP, glucose and cholesterol levels, but excluded smoking and obesity, since the latter did not require a specific screening test performed by a healthcare professional for diagnosis.

At least one of these four major CVRFs (IFG, DM, elevated $\mathrm{BP}$ or hypercholesterolaemia) was present in $75 \%$

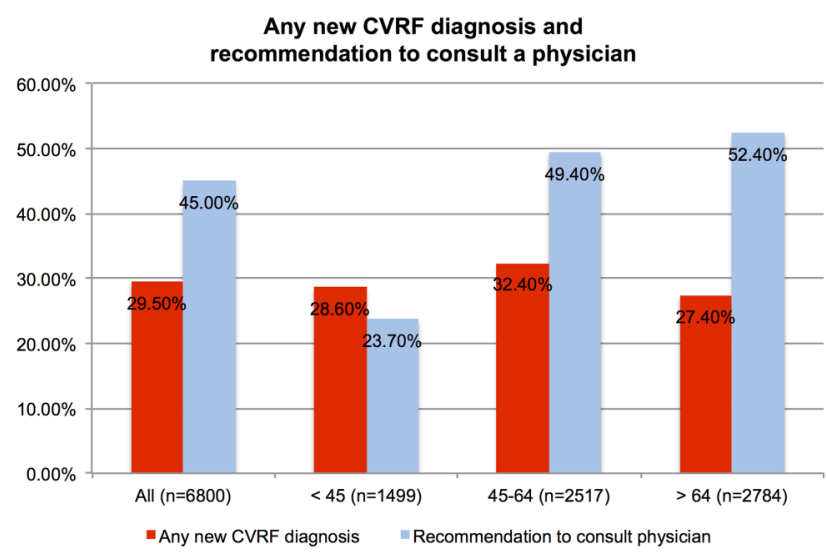

Figure 4 The proportion of patients confronted with a cardiovascular risk factor (CVRF) they were previously unaware of, referring to the instrument based tests (impaired fasting glucose, diabetes, elevated blood pressure and hypercholesterolaemia).

of individuals, similarly frequent in men and women $(\mathrm{p}=0.54$, table 2$)$. Excluding IFG, a CVRF was present in $73.1 \%$ of participants.

Therefore, a new CVRF previously unknown to the participants was identified in $30 \%$ of cases and $45 \%$ of the cohort subsequently received a recommendation to actively consult their physician (figure 4, tables 2 and 3).

When only considering the three CVRF likely requiring pharmacological treatment, hence, excluding IFG, a new diagnosis was established in $28 \%$.

A first-time diagnosis of a CVRF was numerically most likely in the age groups between 25 and 64 (32\% of participants), but still frequent above 64 years $(27 \%$ of participants).

\section{DISCUSSION}

The main finding of our study is that, first, this pharmacy-based approach was able to include a broad population sample in order to identify individuals with previously undiagnosed CVRFs. Overall 30\% of participants were confronted with a CVRF they were previously unaware of, which frequently prompted the pharmacists to recommend an active consultation of a physician. In particular, participants aged between 25 and 64 years gained the greatest benefit in terms of a newly diagnosed CVRF.

Second, this is one of the largest studies assessing all major CVRFs by instrument-based tests at pharmacies, and the first one in Austria. ${ }^{13}$

Previous studies included mostly $<600$ individuals, with heterogeneous results regarding referrals and uptake of referrals, ranging between $6-73 \%$ and $13-83 \%$, respectively. ${ }^{13}$ Overall, the pharmacy-based screening approach was found to be feasible. ${ }^{13}$ In line with our results, the strategy might serve as an easily accessible alternative to the voluntary public preventive medical examination, undertaken by $13 \%$ of adults annually in Austria. ${ }^{5}$ Very 
recently, the RxEACH study recruited 723 patients at high risk for CVD at pharmacies and randomly allocated them to usual care or an intervention, including diagnostic (laboratory) and therapeutic measures. After 3 months, there was a significant $21 \%$ reduction in risk for CVD events through improvements in cholesterol, BP and glycated haemoglobin. The authors concluded that expanding the pharmacists' scope of practice could have significant public health implications. ${ }^{14}$

The crude prevalence of CVRFs was similar to those reported by national surveys, but we observed a substantial likelihood for underdiagnosis in lower age groups. 51516

In the Austrian Health Interview Survey (ATHIS) the prevalence of diabetes was indirectly assessed by the question 'Have you been suffering from diabetes in the past 12 months?'. In the age groups between 45 and 59 years $5 \%$ ( $17 \%$ in our study, fasting patients), and in the age group $\geq 60$ years $12 \%$ (20\% in our study, fasting patients) responded positively to this question. ${ }^{15}$ The mismatch between diagnosed and undiagnosed diabetes was previously outlined by the National Health and Nutrition Examination Survey (NHANES), where, almost identical to our results, DM was identified in $20.9 \%$ above the age of $60 .^{17}$

Also, our study underlines the striking difference between the self-reported (4\%) versus directly assessed (24\%) prevalence of elevated BP below 45 years of age, thus, the likelihood of underdiagnosis of HTN particularly in lower age groups. ${ }^{15}$ We could recently show that in diagnosed, treated and adherent patients approaching a pharmacy in order to obtain their antihypertensive medication, optimal BP control was achieved in only $41 \%$ of patients. $^{18}$ Accordingly, underdiagnosis in affected individuals at a lower age, in addition with inadequate treatment once the condition is diagnosed, inevitably results in an excess of preventable strokes and stroke-related deaths in Austria. ${ }^{19}$

The prevalence of hypercholesterolaemia was comparable to European data obtained by the WHO. ${ }^{20}$ Although recent European guidelines recommend using lowdensity lipoprotein cholesterol as target for treatment, total cholesterol is recommended for the estimation of $\mathrm{CV}$ risk (class I, level of evidence $\mathrm{C}$ ) ${ }^{10}{ }^{10}$ Accordingly, in the setting of pharmacies, the possibility to conveniently obtain total cholesterol levels using a point of care device seems a feasible approach for CV risk screening and referral for further evaluation, if indicated.

Austria is one of the last European countries where the minimum age for purchasing tobacco is 16 years, in turn leading to one of the highest rates of 15-year-olds who smoke at least once a week (29\% of women, $25 \%$ of men). ${ }^{21}$ This was awarded with a Guinness World Record title in $2008 .{ }^{22}$ As a response, the Austrian government passed a bill on a complete smoking ban at public places where food and drinks are served, however, coming only into effect with an inadequately long delay in May 2018. ${ }^{23}$

\section{Limitations}

Although our study is currently the largest and most recent survey directly assessing CVRFs through instrument-based tests, a selection bias due to refusal of consent cannot be excluded. Since screening is usually opportunistic, we did not aim to include a randomly chosen population sample. This might affect the observed crude prevalences of CVRFs.

Owing to time constraints of our survey, prior or current treatment for the investigated conditions was not recorded. Therefore, we might have missed patients with well-controlled risk factors, underestimating the true population-based prevalence of the respective diseases. The assessment of DM might have been biased by a low proportion $(27 \%)$ of fasting participants and was potentially overestimated when using capillary glucose, point of care devices and a cut-off value of $117 \mathrm{mg} / \mathrm{dL}$ as suggested by recent European guidelines. ${ }^{10}$ The assessment of previously unknown CVRFs relied on selfreporting by participants, which is less accurate than extraction from medical reports. In a recent study conducted in pharmacies in Lower Austria we found high awareness for HTN (93\%), thus, the potential bias might be mild in extent. ${ }^{18}$

\section{Conclusion}

This pharmacy-based approach for CV risk screening was able to include 6800 individuals within a 4 months survey period. We found similar overall prevalences of CVRFs as reported by nationwide registries, whereas underdiagnosis was substantial, particularly in the lower age groups. One of the three participants was confronted with a CVRF they were previously unaware of and subsequently, $45 \%$ of the cohort received a recommendation to actively consult a physician. An active screening approach at pharmacies might therefore serve as an alternative to the public preventive medical examination, particularly in younger age groups favouring the convenience and accessibility of such a pharmacy-based programme.

Acknowledgements The authors would like to acknowledge Jan Pazourek from the Health Insurance Fund of Lower Austria, and all participating pharmacists of Lower Austria, who willingly agreed to support their research. This work was also supported by the Association for the Promotion of Research in Atherosclerosis, Thrombosis and Vascular Biology and by the Ludwig Boltzmann Foundation for Cardiovascular Research.

Contributors MR was responsible for data acquisition, statistical analysis and the primary manuscript draft. HH, HS and HK are grant holders, drafted the study protocol and recruited study centres. MT assisted with database handling, and the manuscript draft. MF, KH and TWW provided expertise for statistical analysis, interpretation of data and revised the final manuscript draft. All the authors contributed to and approved the final version of the manuscript.

Funding The study was funded by the Pharmacists College of Lower Austria (Apothekerkammer Niederösterreich) and the Health Insurance Fund of Lower Austria (Niederösterreichische Gebietskrankenkasse, NÖGKK).

Competing interests None declared.

Patient consent Obtained.

Ethics approval Ethics Committee of Lower Austria, Austria. 
Provenance and peer review Not commissioned; externally peer reviewed.

Data sharing statement No additional data are available.

Open Access This is an Open Access article distributed in accordance with the Creative Commons Attribution Non Commercial (CC BY-NC 4.0) license, which permits others to distribute, remix, adapt, build upon this work noncommercially, and license their derivative works on different terms, provided the original work is properly cited and the use is non-commercial. See: http:// creativecommons.org/licenses/by-nc/4.0/

\section{REFERENCES}

1. O'Donnell MJ, Xavier D, Liu L, et al. Risk factors for ischaemic and intracerebral haemorrhagic stroke in 22 countries (the INTERSTROKE study): a case-control study. Lancet 2010;376:112-23.

2. Yusuf S, Hawken S, Ounpuu S, et al. Effect of potentially modifiable risk factors associated with myocardial infarction in 52 countries (the INTERHEART study): case-control study. Lancet 2004;364:937-52.

3. Benson VS, Patnick J, Davies AK, et al. Colorectal cancer screening: a comparison of 35 initiatives in 17 countries. Int $J$ Cancer 2008;122:1357-67.

4. Tenke $\mathrm{P}$, Horti J, Balint $\mathrm{P}$, et al. Prostate cancer screening. Recent Results Cancer Res 2007;175:65-81.

5. Bundesministerium für Gesundheit. Das österreichische Gesundheitssystem-Zahlen, Daten, Fakten. Secondary Das österreichische Gesundheitssystem-Zahlen, Daten, Fakten 2013. http://www.bmg.gv.at/cms/home/attachments/3/4/4/CH1066/ CMS1291414949078/gesundheitssystem-zahlen-daten-2013.pdf

6. Yusuf S, Reddy S, Ounpuu S, et al. Global burden of cardiovascular diseases: part I: general considerations, the epidemiologic transition, risk factors, and impact of urbanization. Circulation 2001;104:2746-53.

7. European Society of Hypertension-European Society of Cardiology Guidelines C. 2003 European Society of Hypertension-European Society of Cardiology Guidelines for the management of arterial hypertension. J Hypertens 2003;21:1011-53.

8. United Nations Statistical Office. Provisional Guidelines on Standard International Age Classifications, Series M, No. 741982.

9. Mancia G, Fagard R, Narkiewicz K, et al. 2013 ESH/ESC Guidelines for the management of arterial hypertension: the Task Force for the Management of Arterial Hypertension of the European Society of Hypertension (ESH) and of the European Society of Cardiology (ESC). Eur Heart J 2013;34:2159-219.

10. Reiner Z, Catapano AL, De Backer G, et al. ESC/EAS Guidelines for the management of dyslipidaemias: the Task Force for the Management of Dyslipidaemias of the European Society of Cardiology (ESC) and the European Atherosclerosis Society (EAS). Eur Heart J 2011;32:1769-818.
11. Ryden L, Grant PJ, Anker SD, et al. ESC Guidelines on diabetes, pre-diabetes, and cardiovascular diseases developed in collaboration with the EASD: the Task Force on Diabetes, Pre-Diabetes, and Cardiovascular Diseases of the European Society of Cardiology (ESC) and developed in collaboration with the European Association for the Study of Diabetes (EASD). Eur Heart J 2013;34:3035-87.

12. Shephard DA. The 1975 Declaration of Helsinki and consent. Can Med Assoc J 1976;115:1191-2.

13. Willis A, Rivers P, Gray LJ, et al. The effectiveness of screening for diabetes and cardiovascular disease risk factors in a community pharmacy setting. PLOS ONE 2014;9:e91157.

14. Tsuyuki RT, Al Hamarneh YN, Jones CA, et al. The effectiveness of pharmacist interventions on cardiovascular risk: the multicenter randomized controlled RxEACH trial. J Am Coll Cardiol 2016;67:2846-54.

15. Federal Ministry of Health. Austrian Health Interview Survey. Secondary Austrian Health Interview Survey, 2014. http://www.bmg. gv.at/cms/home/attachments/1/6/8/CH1066/CMS1448449619038/ gesundheitsbefragung_2014.pdf

16. Griebler R, Geißler W, Winkler P. Zivilisaonskrankheit Diabetes: Ausprägungen-Lösungsansaätze-Herausforderungen. Österreichischer Diabetesbericht, 2013. http://www.oedg.org/pdf/ diabetesbericht_2013.pdf

17. Cowie CC, Rust KF, Byrd-Holt DD, et al. Prevalence of diabetes and impaired fasting glucose in adults in the U.S. population: National Health and Nutrition Examination Survey 1999-2002. Diabetes Care 2006;29:1263-8.

18. Rohla M, Haberfeld $\mathrm{H}$, Tscharre $\mathrm{M}$, et al. Awareness, treatment, and control of hypertension in Austria: a multicentre cross-sectional study. J Hypertens 2016;34:1432-40.

19. Lewington S, Clarke R, Qizilbash N, et al, Prospective Studies C Age-specific relevance of usual blood pressure to vascular mortality: a meta-analysis of individual data for one million adults in 61 prospective studies. Lancet 2002;360:1903-13.

20. The World Health Organization. Global Health Observatory DataRaised Cholesterol-Situation and trends. Secondary Global Health Observatory Data-Raised Cholesterol-Situation and trends. 2008. http://www.who.int/gho/ncd/risk_factors/cholesterol_text/en/

21. Currie C, Zanotti C, Morgan A, et al. Social determinants of health and well-being among young people. Health Behaviour in School-aged Children (HBSC) study: international report from the 2009/2010 survey, 2012. Copenhagen, WHO Regional Office for Europe, 2012 (Health Policy for Children and Adolescents, No. 6).

22. Guinness World Records. Highest percentage of population who smoke (country). 2008. http://www.guinnessworldrecords.de/search? term=austria

23. Parasrampuria DA, Truitt KE. Pharmacokinetics and pharmacodynamics of Edoxaban, a non-vitamin k antagonist ora anticoagulant that inhibits clotting factor Xa. Clin Pharmacokinet 2016:55:641-55. 